\title{
OPTIMAL SCARIFICATION TIMES FOR SEEDS OF TWO MEDITERRANEAN ORCHIDS
}

\author{
EIRINI KATSALIROU ${ }^{1}$, ARGYRIOS GERAKIS ${ }^{2, *}$, \\ and XENOPHON HALDAS ${ }^{3}$ \\ ${ }^{1}$ Department of Food Science and Technology, Ionian University, 28100 Argostoli, Greece \\ ${ }^{2}$ P.O. Box 66, 28100 Argostoli, Greece \\ ${ }^{3} 20$ Tsilimidou St., 28100 Argostoli, Greece \\ * Corresponding author: aris.gerakis@ionio.gr
}

\begin{abstract}
A critical step during the in vitro sexual propagation of Mediterranean orchids is the treatment of seeds with a disinfecting solution that also serves to scarify the seeds. If the seeds are not properly disinfected, microorganisms grow within the culture vessel, thus reducing the efficacy of the process in terms of the extra time and materials required. On the other hand, a long period of disinfection may damage the embryo. The literature is inconclusive with respect to the proper combination of disinfectant strength and duration of the treatment. The objective of this research is to determine the optimal scarification times for two orchid species with thin and thick seed coats, respectively. Seeds of Anacamptis laxiflora (Lam.) and Himantoglossum robertianum (Loisel.) were treated with $0.5 \% \mathrm{NaClO}$ solution for 5, 15, 25, 35, 45, $55,65,75$ and 85 minutes and sown in modified organic Malmgren medium. Logistic regression models were fitted to the results. We found that the longer the chemical treatment, the lower the percentage infection and higher the percentage germination, within the range of times tested. A chemical treatment of 85 minutes in $0.5 \% \mathrm{NaClO}$ results in satisfactory percentage germination for both seeds with relatively permeable seed coats such as A. laxiflora (Lam.) and those with relatively impermeable seed coats such as H. robertianum (Loisel.).
\end{abstract}

Keywords: Anacamptis laxiflora (Lam.); Cephalonia; disinfection; Himantoglossum robertianum (Loisel.); in vitro propagation; Orchidaceae

\section{Introduction}

There are more than 200 species and subspecies of terrestrial orchids recorded in Greece (for example, Petrou et al. 2011; Dimopoulos et al. 2013; Antonopoulos and Tsiftsis 2017; Tsiftsis and Antonopoulos 2017). This remarkable biodiversity is threatened by diverse environmental pressures on their habitats such as cultivation and grazing (Follner et al. 1999; Gerakis et al. 2016; Hirth 2016), urbanisation and tourism (Kretzschmar et al. 2002), illicit collection (Kreziou et al. 2016) and climate change (Hutchings et al. 2018). Meanwhile, the horticultural, nutritional and medicinal value of native orchids remains relatively unexploited. In vitro propagation of native orchids would yield multiple benefits: protection and conservation of valuable genetic resources, the development of an innovative floricultural product for export, manufacture of salep and the possibility of restoring disturbed ecosystems. For this, it is desirable to develop a protocol for in vitro propagation suitable for Mediterranean native orchids that can be used by plant propagation laboratories and professionals for the mass production of seedlings for use in restoration programmes.

The seeds of many wild plants must undergo a process called scarification in order to break embryo dormancy and initiate germination. Scarification literally means "scratching". The first known use of the term is by the comedic playwright Aristophanes (The Frogs, 405 BCE), in reference to the writings of his contemporary philosophers who were ostensibly scribbling nonsense. Large seeds with hard coats often are physically scratched to facilitate imbibition of water. Orchid seeds are too small and fragile, so scarification involves a chemical treatment with a solution that serves two purposes: First, to disinfect the seed in preparation for sowing; second, to break embryo dormancy and initiate germination (Rasmussen 1995). If seeds are not properly disinfected, within a few days fungi, yeasts and occasionally bacteria grow within the culture vessels, reducing the efficacy of the process in terms of the extra time and materials needed. Too short a treatment may result in unduly high infection rates; too long a treatment may damage the embryo. The decision of how long to scarify seeds is further complicated by the fact that different species have seed coats (testas) of different thickness, necessitating different treatment times (Malmgren and Nyström 2018).

Scarification of terrestrial orchid seeds is poorly documented and the sparse evidence is contradictory. For instance, Malmgren and Nyström (2018) recommend soaking the seeds in $0.3-1 \% \mathrm{NaClO}$ solution for 5-45 minutes. On the contrary, Rasmussen (1995) suggests a stronger $\mathrm{NaClO}$ solution (5\%) and much longer treatment times, up to several hours. Further details of the scant literature are provided by Katsalirou et al. (2017). The corollary is that, if mass Mediterranean orchid propagation is ever attempted for commercial or conservation purposes, optimal scarification times must be empirically determined for each species.

Having acquired general experience of in vitro culture of Mediterranean orchids, we initiated a formal experiment to determine optimal seed disinfection times for two species, one with a relatively permeable seed coat, Anacamptis laxiflora (Lam.), and one with a relatively impermeable seed coat, Himantoglossum robertianum (Loisel.). The objective was to determine treatment times that minimize infection of culture vessels and maximize 
seed germination without unduly delaying the in vitro procedure. The first results were reported in Katsalirou et al. (2017). Due to the small number of replications per treatment $(n=8)$, the predictive ability of regression models of percentage infection on treatment duration was no better than the mean percentage infection. However, regression models of percentage germination on treatment duration proved statistically significant or nearly so. Scarification times of only a few minutes in $1 \%$ $\mathrm{NaClO}$ seemed optimal for germination of seeds with relatively permeable seed coats such as those of Anacamptis laxiflora (Lam.). In contrast, scarification times of as long as 45 minutes in $1 \% \mathrm{NaClO}$ were not long enough for seeds with relatively impermeable seed coats such as those of Himantoglossum robertianum (Loisel.). The lessons learned from that study were:

a) Eight replications are too few to obtain statistically significant results.

b) For seeds with relatively permeable coats, a weaker $\mathrm{NaClO}$ solution is better for controlling the scarification process as the treatment is more prolonged.

In this study, we repeat the experiment with more replications per treatment, weaker $\mathrm{NaClO}$ solution and longer treatment times.

\section{Materials and Methods}

\section{Preparation of disinfecting solution}

As a stock solution, we used a commercial formulation of household bleach (Klinex', Unilever) with a nominal $\mathrm{NaClO}$ concentration of $4.8 \% \mathrm{w} / \mathrm{w}$. To verify the strength of the formulation, we titrated three different volumes (5, 10, and $20 \mathrm{~mL}$ ) with $\mathrm{AgNO}_{3}$ solution following Mohr's method (Harris 2010). The manufacturer's reported concentration was found to be accurate. The stock solution was diluted with deionised water to a final concentration of $0.5 \%$. Four drops of dish detergent per litre were added to reduce surface tension.

\section{Experimental treatments}

Combinations of nine treatment durations $(5,15,25$, $35,45,55,65,75$ and 85 minutes) and two orchid species were tested. The two species were selected based on the permeability of their seed coats; a species with a relatively permeable seed coat, Anacamptis laxiflora (Lam.), and a species with a relatively impermeable seed coat, Himantoglossum robertianum (Loisel.).

In a proper factorial experiment, combinations of treatments are assigned to culture vessels at random. However, this means we would have to keep track of nine different treatment durations per experimental run, unduly increasing the complexity of the experimental setup and the possibility of operator error. Instead, we tested one treatment duration per experimental run, in reverse order; the longest duration was tested first to minimize the effect of operator learning. Had we proceeded the opposite way, we would give undue credit to the longest duration as a result of the operator improving his or her technique. Although operator experience can be an important factor in specialized work, such as in vitro propagation, this factor should best be tested in a separate experiment.

Each experimental run consisted of 24 culture vessels per species that served as experimental replications plus eight "blanks", i.e., culture vessels without seed. The blanks were subject to the same treatment as the vessels with seed, including simulated sowing with imaginary seed. The purpose of the blanks was to reveal possible shortcomings of our technique that were not due to seedborne contaminants.

\section{Field method}

The seeds were collected on the island of Cephalonia, Greece. At flowering, healthy and robust individuals of Himantoglossum robertianum (Loisel.) and Anacamptis laxiflora (Lam.) were identified in the field, photographed, labelled and recorded. At senescence, seed was collected from mature capsules. Both species are abundant enough so that seed collection did not jeopardize the natural populations. The seeds were sieved to remove foreign matter such as capsule fragments, dried in a desiccator with silica gel, sealed in glass vials and stored at $-20{ }^{\circ} \mathrm{C}$ until sowing.

\section{Laboratory method}

In nature, germinating orchid seeds develop a symbiotic association with fungi that supply them with nutrients. The seeds have almost no nutrient reserves of their own, so that germination depends on a fungus-orchid association called mycorrhiza (Garbaye 2013). It is possible to reproduce the mycorrhizal association in the laboratory. Although this approach most closely mimics nature, it is complicated because the operator must manage two organisms instead of one. Instead, many practitioners opt for a sterile nutrient solution that supplies the seed with the nutrients necessary for germination and early development.

\section{Preparation of nutrient medium}

There exist numerous recipes for nutrient media for propagating terrestrial orchids (Rasmussen 1995). A few base ingredients are included in most recipes, which makes sense, as most terrestrial plants require the same 16 nutrients for growth and development (Marschner 1995). Some recipes add unusual elements such as $\mathrm{Al}$ and I, the benefit of which has not been unequivocally demonstrated; others add tropical fruit juices or tree sap, the role of which has yet to be explained. We opted for a modified version of "SM-organic" (Rasmussen 1995), a time-tested formula used by veteran practitioner Svante Malmgren. The medium is termed "organic" on account of its $\mathrm{N}$ source, an amino acid mixture sold under the trade name Vaminolac. However, in Greece 
Table 1 Formula for modified "SM-organic" nutrient medium

\begin{tabular}{|l|c|}
\hline Ingredient & Quantity \\
\hline Mineral water to make & $1 \mathrm{I}$ \\
\hline $\mathrm{CaHPO}_{4}$ & $99 \mathrm{mg}^{\mathrm{a}}$ \\
\hline $\mathrm{KH}_{2} \mathrm{PO}_{4}$ & $75 \mathrm{mg}$ \\
\hline $\mathrm{MgSO}_{4} \cdot 7 \mathrm{H}_{2} \mathrm{O}$ & $75 \mathrm{mg}$ \\
\hline Soluvit (water soluble vitamins) & $10 \mathrm{ml}$ \\
\hline Amina-Fe & $0.92 \mathrm{ml}$ \\
\hline Kinetin & $5 \mathrm{mg}$ \\
\hline Saccharose (sucrose) & $10 \mathrm{~g}$ \\
\hline Activated charcoal, powdered & $12 \mathrm{~g}$ \\
\hline Danish agar & $25 \mathrm{ml}$ \\
\hline Pineapple (Ananas comosus) juice & $1-2 \mathrm{drops}$ \\
\hline NH & or HCl for pH adjustment \\
\hline Potato (Solanum tuberosum) tuber & $1 \mathrm{~cm}^{3}$ per culture vessel \\
\hline
\end{tabular}

a Equivalent to $75 \mathrm{mg} \mathrm{Ca}_{3}\left(\mathrm{PO}_{4}\right)_{2}$ in the original formula.

b Equivalent to $0.5 \mathrm{ml} \mathrm{Vaminolac}{ }^{\circledR}$ plus $10 \mathrm{mg} \mathrm{FeSO}_{4}$ in the original formula.

Vaminolac is considered a medicine and as such cannot be sold without physician's prescription. Therefore, we substituted Amina-Fe (Humofert), a liquid fertiliser containing amino acids and chelate Fe. Because the addition of Amina-Fe more than covers the Fe requirement in Malmgren's recipe, we omitted the ferrous salt of the original formula. Further, we substituted $\mathrm{CaHPO}_{4}$ for $\mathrm{Ca}_{3}\left(\mathrm{PO}_{4}\right)_{2}$. Mineral water was substituted for tap water, on account of the high salinity of the municipal water supply (electrical conductivity at $25^{\circ} \mathrm{C}>1 \mathrm{mS} \mathrm{cm}^{-1}$ ). The formula is in Table 1.

The ingredients were mixed in a 11 Erlenmeyer flask placed on a hot plate with a magnetic stirrer. After the solution cooled to ambient temperature, $\mathrm{pH}$ was adjusted to 5.5-6.0 with either $\mathrm{NH}_{3}$ or $\mathrm{HCl}$.

\section{Preparation of materials}

The nutrient medium was evenly distributed to $250 \mathrm{ml}$ Erlenmeyer flasks for autoclaving. Glassware, steel tools, filter paper, potato cubes and deionized water were also sterilized in the autoclave, a Tuttnauer 2340 programmed on a 30 minute cycle (for cold departure) or a 25 minute cycle (for hot departure) at a temperature of $121^{\circ} \mathrm{C}$ and pressure of 1.2 bar.

The sowings were carried out inside an Esco EQU/04EBC-2A laminar flow cabinet. The interior surfaces were wiped with cotton wool soaked in $70 \% \mathrm{v} / \mathrm{v}$ ethanol. The culture vessels were $100 \mathrm{~mL}$ urine samplers made of polypropylene, individually wrapped in sterile packaging. All non-autoclavable materials were placed in the laminar flow cabinet and exposed to a germicidal UV lamp for 50 minutes. The workspace outside the laminar flow cabinet was also disinfected with a germicidal UV lamp for 50 minutes. The airflow in the cabinet was
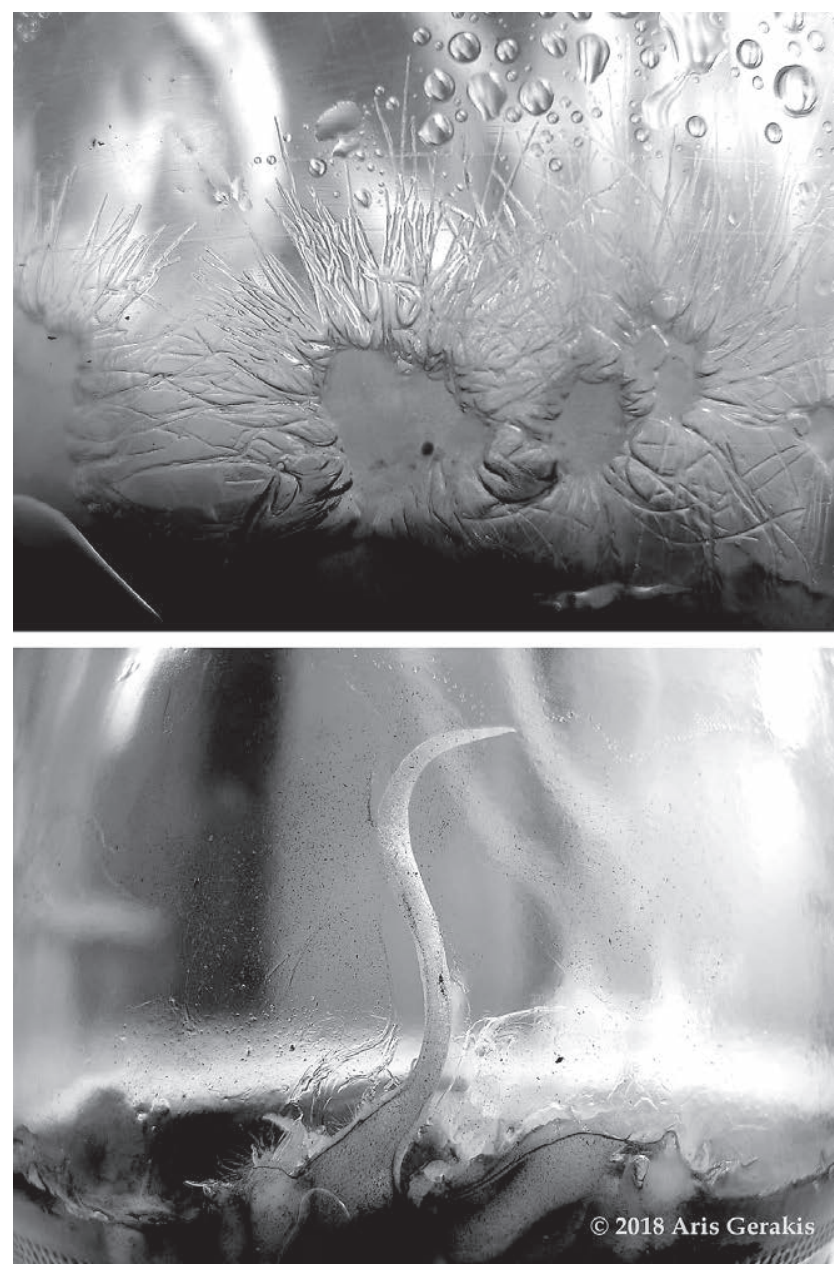

Fig. 1 Photographs of germinated seed: (a) Anacamptis laxiflora (Lam.), a few weeks after sowing and (b) Himantoglossum robertianum (Loisel.), a few months after sowing.

turned on for 15 minutes to purge airborne contaminants as per manufacturer's instructions. ${ }^{1}$ The sterile seal of the culture vessels was broken. The Erlenmeyer flasks with the nutrient medium were transferred from the autoclave onto a hotplate inside the laminar flow cabinet with the thermostat set to $50{ }^{\circ} \mathrm{C}$.

\section{Seed Disinfection}

The seeds were disinfected in glass test tubes sealed with a cap. Ninety mg of seed was scooped up with a spatula and placed in each tube, except those assigned as blanks. The test tubes were filled nearly to the top with disinfecting solution, capped and shaken vigorously to remove any air bubbles in contact with the seed. The shaking was repeated every 15 minutes thereafter till the end of the disinfection period.

At the end of the disinfection period, the suspensions were decanted into Erlenmeyer flasks fitted with a polypropylene funnel lined with filter paper to recover the

1 Esco $^{\circ}$. Class II Type A/B3 Biohazard Safety Cabinets. User Operation Manual. 
seed. The filter paper was soaked in the same disinfecting solution as the seed. After filtering the suspensions, each filter paper was rinsed five times with approximately $7 \mathrm{ml}$ of sterile deionized water.

\section{Sowing}

Each culture vessel was filled with approximately $17 \mathrm{ml}$ of sterile nutrient medium and a potato cube. Once the nutrient medium cooled down to about $35^{\circ} \mathrm{C}$, the seeds were scraped from the filter paper using a spatula and distributed in the culture vessels. The tips of the steel tools were heat sterilized between sowing.

The culture vessels were incubated in a dark cabinet at an ambient temperature of $22{ }^{\circ} \mathrm{C}$. Forty one days after the final sowing, the vessels were visually examined for the development of fungus, yeast and bacterial colonies. The infected vessels were counted and the non-infected vessels were returned to the cabinet. After 189 days, the vessels with germinated seeds were counted. Fig. 1 shows the germinated seeds of the two species.

\section{Statistical methods}

Because the response variables are nominal (infected vs. non-infected, germinated vs. non-germinated), one way to analyse the responses is by logistic regression (SAS Institute 2003). The probability of a nominal response with two levels (e.g., germinated vs. non-germinated) is modelled as a function of a regressor (in this case, treatment duration):

$\% \mathrm{P}(Y=1$ st response $)=1 /\left[1+\mathrm{e}^{-(\beta 0+\beta 1 X)}\right] \times 100$

$\% \mathrm{P}(Y=2$ nd response $)=100-\% \mathrm{P}(Y=1$ st response $)(2)$

where $\% \mathrm{P}$ is percent probability, $Y=$ nominal response, $X=$ regressor and $\beta_{0}, \beta_{1}=$ fitting parameters. The level of significance for statistical tests was set $a$ priori at $\alpha=0.05$.

\section{Results and Discussion}

The infection rate for the 72 "blank" vessels was nil, which proves that our technique was valid and that all contamination came from the seed. The percentage germination for the 72 "blank" vessels also was nil, naturally. As far as the vessels with seed, we noticed that the seed in any vessel that was not infected, germinated. This greatly simplified subsequent calculations, because all we had to model was either the percentage infection or the percentage germination for any given treatment, as they summed up to $100 \%$. Of course, at the end of the day what matters most is percentage germination, because that determines how many useable seedlings are produced. Percentages germination for the two species are compared in Fig. 2. Logistic regression models were significant for both species. The statistical output is in Table 2 .

The models of percentage germination in Fig. 2 are derived from eq. (1) substituting the parameter estimates from Table 2 . To model percentage infection, we reverse the sign of the parameters, i.e., $\beta_{0}=2.6647, \beta_{1}=-0.0574$ for A. laxiflora and $\beta_{0}=1.2824, \beta_{1}=-0.0344$ for $H$. robertianum.

A notable result is that a weaker $\mathrm{NaClO}$ solution ( 0.5 as opposed to $1 \%$ ) affords better control of the scarification process of seeds with a relatively thin testa such as those of A. laxiflora. Seeds with thin testa imbibe solution fast. Katsalirou et al. (2017) demonstrate that seeds of A. laxiflora can only be kept for a few minutes in $1 \%$ $\mathrm{NaClO}$ solution before their viability is reduced. However, too short a treatment may cause the operator to rush, increasing the possibility of error. In addition, it raises the question whether the time it takes to fill up, agitate and empty the test tubes containing the disinfectant solution should count toward the time necessary for scarification. For the longer treatment times afforded by weaker solutions, the answer is not critical.

Table 2 Model test and parameter estimates for logistic regression of percentage germination on treatment duration: $L L=$ log likelihood, DF = degrees of freedom, $X^{2}=$ chi-square, $p=$ probability, $R^{2}=$ ratio of "Difference" to "Reduced" $L L, \beta_{0}$ and $\beta_{1}=$ fitted parameters.

\begin{tabular}{|c|c|c|c|c|c|c|c|c|}
\hline \multicolumn{9}{|c|}{ Whole Model Test } \\
\hline & \multicolumn{4}{|c|}{ Anacamptis laxiflora (Lam.) } & \multicolumn{4}{|c|}{ Himantoglossum robertianum (Loisel.) } \\
\hline Model & $-\mathrm{LL}$ & DF & $x^{2}$ & $p>x^{2}$ & $-\mathrm{LL}$ & DF & $x^{2}$ & $p>X^{2}$ \\
\hline Difference & 40.04 & 1 & 80.08 & $<.0001$ & 17.91 & 1 & 35.83 & $<.0001$ \\
\hline Full & 109.60 & & & & 130.47 & & & \\
\hline Reduced & 149.64 & & & & 148.38 & & & \\
\hline$R^{2}$ & 0.27 & & & & 0.12 & & & \\
\hline Observations & 216 & & & & 216 & & & \\
\hline \multicolumn{9}{|c|}{ Parameter Estimates for Log Odds of P(germinated) / P(non-germinated) } \\
\hline Term & Estimate & SE & $x^{2}$ & $p>x^{2}$ & Estimate & SE & $x^{2}$ & $p>X^{2}$ \\
\hline Intercept $\left(\beta_{0}\right)$ & -2.6647 & 0.39 & 45.82 & $<.0001$ & -1.2824 & 0.30 & 17.75 & $<.0001$ \\
\hline Duration $\left(\beta_{1}\right)$ & 0.0574 & 0.01 & 54.47 & $<.0001$ & 0.0344 & 0.01 & 30.54 & $<.0001$ \\
\hline
\end{tabular}



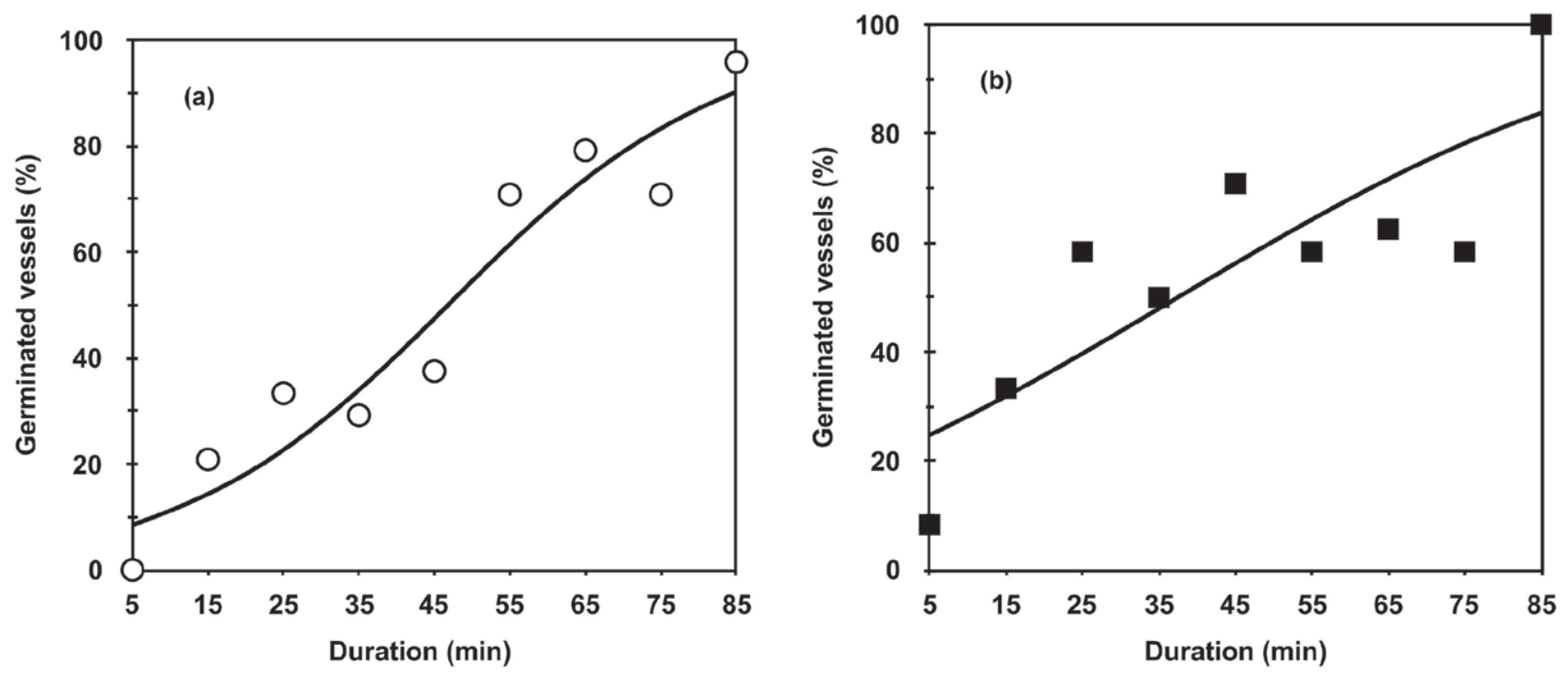

Fig. 2 Effect of treatment duration on percentage germination of (a) Anacamptis laxiflora (Lam.) and (b) Himantoglossum robertianum (Loisel.), 189 days after sowing. Markers are measured points $(n=24)$ and curves are fitted models. The models are derived from eq. (1) substituting parameter estimates from Table 2.

From Fig. 2 it follows that the longer the chemical treatment, the lower the predicted percentage infection and the higher the predicted percentage germination, within the range of times tested. A chemical treatment of 85 minutes in $0.5 \% \mathrm{NaClO}$ results in satisfactory predicted percentage germination for both species, namely $90 \%$ for A. laxiflora and $84 \%$ for $H$. robertianum. Prolonging the treatment beyond 85 minutes will not necessarily improve percentage germination and in fact may reduce seed viability. In this sense, while regression models can be useful to illustrate the difference in scarification times among various species, they should not be extrapolated outside the range of tested times to avoid unwarranted conclusions.

In light of these results and those of our earlier study (Katsalirou et al. 2017), the advice of Malmgren and Nyström (2018) to soak terrestrial orchid seeds in $0.3-1 \% \mathrm{NaClO}$ solution for $5-45$ minutes is only a general recommendation. We found that a few minutes more or less can make the difference between a successful and an unsuccessful sowing. Rasmussen's (1995) recommendation of a stronger $\mathrm{NaClO}$ solution (5\%) and treatment of up to several hours for Dactylorhiza maculata and Epipactis helleborine would probably harm the seeds of the two species that we tested. In conclusion, there is no easy way to predict optimal scarification times for seeds of terrestrial orchids, short of testing each species individually.

Artificial propagation of native orchids can be helpful to conserve populations threatened by extinction, especially stenoecious taxa, i.e., those confined to a rare habitat. Once the habitat is lost, so is the population. The first step in a conservation project would be to identify populations at risk and collect seed to establish a seed bank. The second step would be to cultivate plants from seed with a two-fold purpose: (a) to further multiply the seed and (b) to re-establish plants at suitable locations. Pos- sible fields of application include: (a) restoration of disturbed habitats, such as quarries, mines and road banks, (b) mitigation of environmental effect of public works, (c) preservation of populations in coastal habitats (e.g., sand dunes) threatened by sea level rise, and (d) enrichment of orchid collections of botanical gardens.

\section{Conclusions}

Chemical scarification of seeds is a critical step in the in vitro propagation of Mediterranean orchids. On the one hand, too short a treatment may result in a high percentage of infected vessels, which translates into a waste of labour and material resources. On the other hand, unduly long treatments slow down the procedure and may reduce seed viability. Empirically derived regression models are useful for illustrating the difference in the scarification requirements of various species. In our case, a scarification time of 85 minutes in $0.5 \% \mathrm{NaClO}$ resulted in a satisfactory predicted percentage germination for both seeds with relatively permeable seed coats (Anacamptis laxiflora Lam.) and those with relatively impermeable seed coats (Himantoglossum robertianum Loisel.). For statistically significant results, the appropriate number of replicates need to be determined; 24 replicates per treatment proved adequate for this study.

\section{Acknowledgements}

We are indebted to Pierre Walter for invaluable technical assistance with in vitro propagation. We thank the Department of Food Science and Technology of the Ionian University (formerly Technological Educational Institute of Ionian Islands) for access to its laboratory facilities. 


\section{REFERENCES}

Antonopoulos Z, Tsiftsis S (2017) Atlas of the Greek Orchids. Vol. II. Mediterraneo Editions, Rethymno.

Dimopoulos P, Raus T, Bergmeier E, Constantinidis T, Iatrou G, Kokkini S, Strid A, Tzanoudakis D (2013) Vascular plants of Greece: an annotated checklist. Botanic Garden and Botanical Museum Berlin-Dahlem, Freie Universität Berlin and the Hellenic Botanical Society, Athens.

Follner K, Antzoulatos Y, Blank S, Klarenberg A, Panou A, Mommertz S (1999) Effects of grazing on the Abies cephalonica (Loudon) forest of Mount Ainos (island of Cephalonia, Ionian Sea, Greece). Contributions to the Zoogeography and Ecology of the Eastern Mediterranean Region 1: 83-88.

Garbaye J (2013) La symbiose mycorhizienne: une association entre les plantes et les champignons. Editions Quae, Versailles.

Gerakis A, Haldas X, Giannakoulias M (2016) Anacamptis palustris subsp. robusta (Orchidaceae): a new record to the flora of Cephalonia. Greece J Eur Orch 48: 11-18.

Harris DC (2010) Quantitative chemical analysis. 8th ed. W. H. Freeman, San Francisco, CA.

Hirth M (2016) A long-term survey of orchids on the small Greek Island Agathonisi from 1994 to 2013. J Eur Orch 48: 37-52.

Hutchings MJ, Robbirt KM, Roberts DL, Davy AJ (2018) Vulnerability of a specialized pollination mechanism to climate change revealed by a 356-year analysis. Bot J Lin Soc 186: 498-509, https://doi.org/10.1093/botlinnean/box086.

Katsalirou E, Gerakis A, Haldas X, Deconninck G (2017) Optimal disinfection times for seeds of Mediterranean orchids propagated on nutrient media. Eur J Environ Sci 7: 119-124, https://doi .org/10.14712/23361964.2017.10.

Kretzschmar H, Kretzschmar G, Eccarius W (2002) Orchideen auf Kreta, Kasos und Karpathos: Ein Feldführer durch die Orchideenflora der zentralen Inseln der Südägäis. Selbstverlag H. Kretzschmar. Bad Hersfeld.

Kreziou A, De Boer H, Gravendeel B (2016) Harvesting of salep orchids in north-western Greece continues to threaten natural populations. Oryx 50: 393-396, https://doi.org/10.1017 /S0030605315000265.

Malmgren S, Nyström H (2018) Orchid propagation. http://www lidaforsgarden.com/orchids/engelsk.htm. Accessed 4 Dec 2018.

Marschner H (1995) Mineral nutrition of higher plants. Academic Press, San Diego, CA.

Petrou N, Petrou M, Giannakoulias M (2011) Orchids of Greece. Koan/Eight Clouds, Athens. Rasmussen HN (1995) Terrestrial orchids: From seed to mycotrophic plant. Cambridge U. Press, Cambridge.

SAS Institute (2003) JMP statistics and graphics guide. Version 5.1.2. SAS Institute, Cary, NC.

Tsiftsis S, Antonopoulos Z (2017) Atlas of the Greek Orchids. Vol. I. Mediterraneo Editions, Rethymno. 